\title{
Stepped Impedance Microstrip Lowpass Filter Design using Advanced Design Systems
}

\author{
Ayibapreye Kelvin Benjamin*, Priye Kenneth Ainah ${ }^{* *}$, Animiosevbuse Tosan Enoma ${ }^{* * * *}$ \\ * Department of Electrical/Electronic Engineering, Niger Delta University \\ ${ }^{* *}$ Department Electrical/Electronic Engineering, Niger Delta University \\ *** Department Electrical/Electronic Engineering, Niger Delta University \\ DOI: 10.29322/IJSRP.11.07.2021.p11548 \\ http://dx.doi.org/10.29322/IJSRP.11.07.2021.p11548
}

\begin{abstract}
This paper describes an advanced design systems (ADS) approach of stepped impedance microstrip low pass filter design for maximally flat or Butterworth responses. The cut-off frequency is $4 \mathrm{GHz}$ with source and load impedances of $50 \Omega$. The insertion loss at passband is $0.5 d B$ and stopband is $20 d B$. In this filter design, an order $N=7$ was chosen for maximally flat (Butterworth) filter prototype. Substrate properties such as relative dielectric constant $\epsilon_{r}=4.2$, loss tangent $\tan \delta=0.02$, height of dielectric material $h=2.0 \mathrm{~mm}$ and conductor thickness of $0.01 \mathrm{~mm}$ were used in calculation of the length and width of the transmission line. Design of lumped circuit for microwave filter prototype scaled in frequency and impedances is discussed. Equivalent transmission line was obtained by converting lumped circuit into certain lengths and characteristic impedances. ADS simulation software was used to plot maximally flat filter characteristics. The plots show variation of incident wave $S(1,1)$ and forward gain $S(1,2)$ with frequency in $G H z$.
\end{abstract}

Index Terms- Stepped impedance, Lowpass filter, Microstrip, Advanced design systems.

\section{INTRODUCTION}

$\mathrm{T}_{\mathrm{r}}^{\mathrm{h}}$ he control of frequency response at a certain point in a radio frequency $(\mathrm{RF})$ or microwave system is implemented by a filter as a two-port network by providing transmission at frequencies within the passband of the filter and attenuation in the stopband of the filter. Band reject characteristics, bandpass, lowpass, and high-pass are typical filter responses. Microwave filters have applications in almost any class of RF or microwave communication, radar, or test and measurement system [1]. Filter theory and practice was developed in the early years before World War II by researchers such as Mason, Darlington, Sykes, Fano, Lawson and Richards. In the late 1930s, the image parameter method of filter design was developed and became prominent for low frequency filters in telephony and radio. Microwave filter and coupler development became very popular in the early 1950s due to contributions from a research group at Stanford Research Institute. Today, cutting-edge and state of the art computer-aided design (CAD) packages based on insertion loss method are used in microwave filter design. Microwave filter design remains an active area of research due to incessant growth and advances in network synthesis with distributed elements, deployment of low- cost temperature semiconductors and other materials, and the connection of active devices in filter circuits [1]-[2].

Filter theory and design have frequency characteristics with periodic structures, which comprised of a transmission line or waveguide periodically loaded with reactive elements. Periodic structures are of interest in filter design for their use in slow-wave components and travelling wave design, and also as they display basic passband-stopband responses that give rise to the image parameter method of filter design. Microwave filters are two-port network used to control the frequency response at certain point in a microwave system by signal transmission at frequencies within the passband of the filter and attenuation within the stopband of the filter. The incessant increase in demand and specification levels of microwave filters for advanced communication systems have necessitated research interest in both industry and academia. Hence, microwave filter designs are becoming very popular [1][6].

Maximally flat (Butterworth) filter, Chebyshev filter and Bessel filter are realizable filters often used in the design of microwave low-pass filter. The use of maximally flat low-pass filter raises contradiction concerns between stability, response time and test precision. Maximally flat filter with low order $N$ has characteristics such as small filter overshoot, rapid response and bad test precision. High-order maximally flat low-pass filters have good test precision, large overshoot, poor stability and slow response [5]-[6]

This filter has a type of construction called reflective filter and consists of capacitive and inductive elements that gives ideally zero reflection loss in the passband region and very high attenuation in the stopband region. An ideal or perfect filter do not exist in practice, to achieve a near ideal filter compromises are made which are inherent in filter design. A perfect filter should have zero insertion loss in the passband, infinite attenuation in the stopband, and in the passband-a linear phase response to avoid signal distortion [6]-[7].

Shreyasi. et.al [8]-[13] presented the design technique, fabrication, simulation and comparison between measured and simulated results of microstrip parallel coupled bandpass filter. This was designed and optimized at $2.44 \mathrm{GHz}$ with a fractional bandwidth (FBD) of $3.42 \%$. The usual design procedure of first calculating the lumped components and develop their prototype was adopted. Shreyasi et. al used an admittance inverter to transform the lumped circuit into an equivalent distributed circuit using microwave structures. Filter specifications such width w, 
thickness $h$ and dielectric constant of substrate $\epsilon$ were used to realize the filter structure using parallel coupled technique. Advanced design systems (ADS) software was used in simulating microstrip filter characteristics. An optimization was carried out to obtain low insertion loss and selective skirt. The filter was fabricated on Flame Retardant (FR-4) and comparison between simulated and measured results were reported. The insertion loss for test results were slightly more $(1.5 \mathrm{~dB})$ than the simulated results which may be due to fabrication anomalies, FR-4 material losses and disparity in dielectric constants can be attributed to the reason for higher insertion loss.

Ninikrishna et. al [14]-[15] designed a microstrip low-pass filter by insertion loss method using two electrical lengths of $230^{\circ}$ and $90^{\circ}(\lambda / 4)$ transmission lines. Repeating characteristics of low-pass filter amplitude response was obtained using Richardson's transformation. To obtain sharp rejection within a cut-off frequency of $10 \mathrm{GHz}$ which was highest, the electrical length was $90^{\circ}$. Ninikrishna et. al used an analysis technique very effective for harmonic suppression, and have spurious frequencies in the stopband. It is widely deployed for radar applications. Realization of the low-pass filter was achieved by the use of distributed elements that were obtained by various transformations such as Richard's transformation, Kuroda's identity and the concept of unit elements. This design gives a perfect property of low insertion loss in the passband and infinite attenuation in the stopband. Due to the incessant demand to meet ever-growing telecommunication challenges faced by microwave systems due to size, cost and performance of microwave devices, there is need to design microstrip low-pass filters that transmit signals at microwave frequency. In this project, a microstrip stepped impedance low-pass filter with insertion loss of $0.5 \mathrm{~dB}$ at cut-off frequency $4 \mathrm{GHz}$ and attenuation of $20 \mathrm{~dB}$ at stopband frequency $6 \mathrm{GHz}$, with given substrate properties such as relative dielectric constant $\epsilon_{r}=4.2$, loss tangent $\tan \delta=0.02$, height of dielectric material $h=2.0 \mathrm{~mm}$ and conductor thickness of $0.01 \mathrm{~mm}$ was designed for order $N=7$ maximally flat (Butterworth) filter lowpass prototype and $N=5$ Chebyshev low pass filter prototype. This designed was projected to achieve a harmonic suppression of $-20 \mathrm{~dB}$ at stopband frequency of $6 \mathrm{GHz}$.

\section{STEPPED IMPEDANCE LOW-PASS FILTER DESIGN PROCEDURE}

Simulation of lumped elements in the filter circuit can be realize using waveguides, coaxial lines, strip or microstrip lines, cavity resonators, etc. The equivalent circuit which comprised of lumped element values of the microwave components are mainly functions of frequency. Microwave filter design of various types operating at arbitrary frequency bands and within arbitrary resistive loads, are developed from a prototype low-pass design through

1. Frequency transformers.

2. Normalization of lumped elements and its simulation through sections of transmission lines.

3. Design of low-pass filter prototype with unique passband characteristics.
4. The prototype network is transformed to the specified type (low-pass, high-pass, and band-pass) filter with the cut-off and stopband frequencies.

5. The distributed network in microwave form is realized using sections of microwave transmission lines.

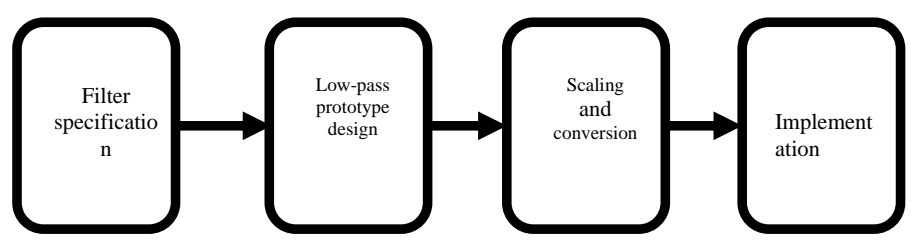

Figure 1. Filter design procedure by insertion loss method

A. Design of Maximally Flat Low-Pass Filter

The appropriate order of filter, $N$ is determined for given filter specifications. For maximally flat filter characteristic we can obtain the order of the filter that satisfies characteristics by:

$N \geq \frac{I L\left(\omega_{c}\right)+I L\left(\omega_{s}\right)}{20 \log \left(\frac{\omega_{S}}{\omega_{c}}\right)}$

Insertion loss at $\omega_{c}\left(I L\left(\omega_{c}\right)\right)=0.5 d B$

Insertion loss at $\omega_{S}\left(I L\left(\omega_{S}\right)\right)=20 d B$

The cut-off frequency or passband frequency $=4 \mathrm{GHz}$

The stopband frequency $=6 \mathrm{GHz}$

$$
\begin{aligned}
& N \geq \frac{0.5 d B+20 d B}{20 \log \left(\frac{6}{4}\right)} \\
& N \geq \frac{20.05 d B}{20 \log (1.5)}
\end{aligned}
$$

$N \geq 5.82$.

Odd number filters give better roll-off and frequency response and higher order helps to provide low attenuation at high frequency. Hence, the need to choose an order of 7 instead of 5.

Table 1. Shows element values for maximally flat low-pass filter prototype $\left(g_{o}=1, \omega_{c}=1, N=7\right)$

\begin{tabular}{|c|c|c|c|c|c|c|c|c|}
\hline $\mathrm{N}$ & $g_{1}$ & $g_{2}$ & $g_{3}$ & $g_{4}$ & $g_{5}$ & $g_{6}$ & $g_{7}$ & $g_{8}$ \\
\hline 7 & 0.445 & 1.247 & 1.802 & 2.0 & 1.802 & 1.247 & 0.445 & 1.0 \\
\hline
\end{tabular}




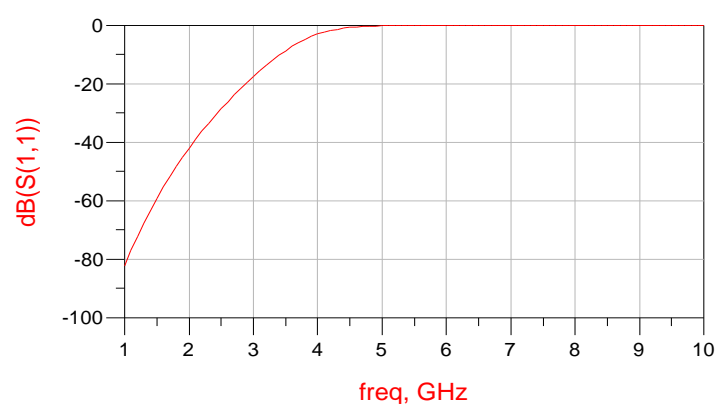

Figure 2. The characteristic of the microwave filter showing variation of incident wave with frequency

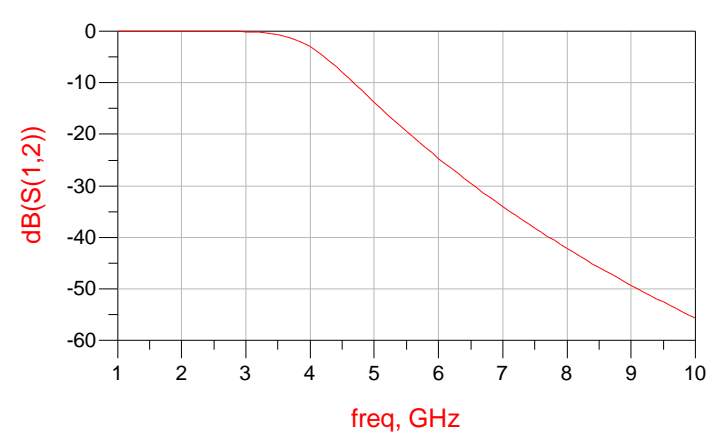

Figure 3. The characteristic of the microwave filter showing variation of the forward gain with frequency

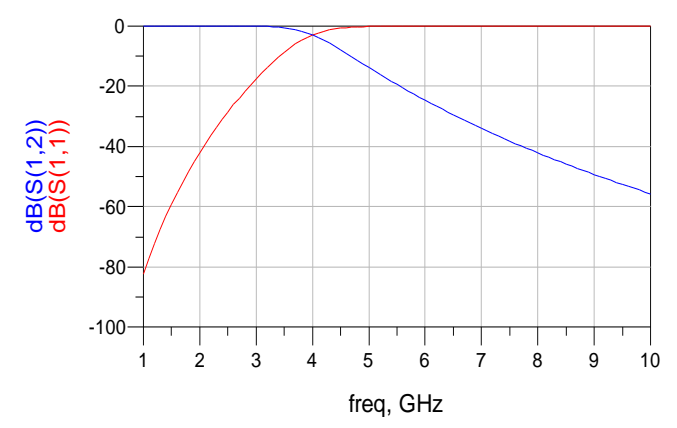

Figure 4. The characteristic of the microwave filter showing variation of both incident wave and the forward gain with frequency

The figures above illustrate that the microwave filter design met the specification of the maximally flat low-pass filter design specification as the incident wave and forward gain intercept at 4 GHz. In figure 2 and figure 4 the cut-off frequency of $4 \mathrm{GHz}$ was obtained.

B. Design of Microwave Filter Prototype (L and C Elements) Scaled for the Given Frequency Band and $50 \Omega$ Input and Output Impedance.
The coefficients were converted into a microwave prototype network by impedance and frequency scaling utilizing the equations as follows:

$L^{\prime}=\frac{R_{o} L}{\omega}, C^{\prime}=\frac{C}{R_{o}}, \beta l=\frac{L^{\prime}}{Z_{O L}}$, given that $R_{O}=50 \Omega$,

Table 2. Shows lumped element values of the capacitor and inductor for maximally flat low pass filter prototype $\left(g_{o}=\right.$ $\left.50 \Omega, g_{8}=50 \Omega\right)$

Figure 5. Lumped circuit for maximally flat low-pass filter prototype obtained from ADS software.
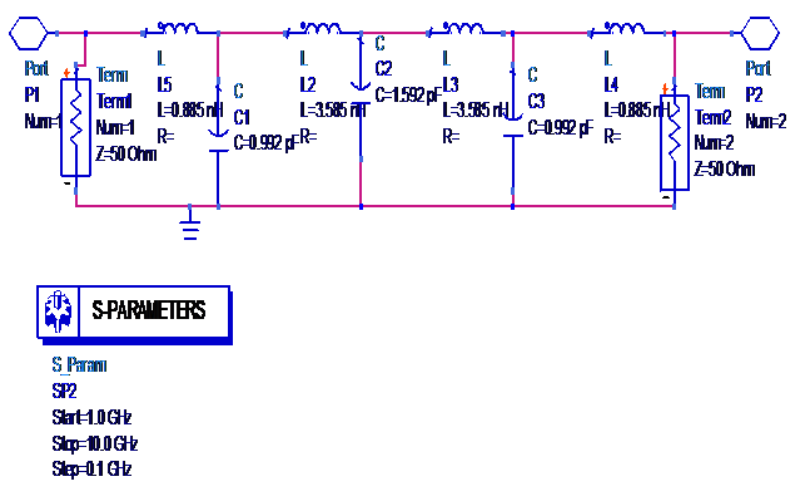

C. Equivalent Transmission Line Filter obtained by Converting the Capacitors and Inductors of the Lumped Circuit into Transmission Lines of Certain Lengths and Characteristic Impedances.

To obtain the equivalent transmission line filter we have to convert the capacitors and inductors of the lumped circuit into transmission lines of certain lengths and characteristic impedances. This is obtained by the equations below;

$L^{\prime}=R_{O} L, C^{\prime}=\frac{C}{R_{O}}, L=Z_{O L} \beta l, C \frac{\beta l}{z_{o c}}$, where $R_{O}=50 \Omega$

From these calculations the above transmission line parameters were obtained as shown in Table 3.

Table 3. Shows distributed network parameters.

\begin{tabular}{|c|l|l|l|l|l|l|l|l|}
\hline$g_{o}$ & $g_{1}$ & $g_{2}$ & $g_{3}$ & $g_{4}$ & $g_{5}$ & $g_{6}$ & $g_{7}$ & $g_{8}$ \\
& $-L_{1}$ & $-c_{1}$ & $-L_{2}$ & $-c_{2}$ & $-L_{3}$ & $-c_{3}$ & $-L_{4}$ & \\
\hline & 0.885 & 0.992 & 3.538 & 1.592 & 3.585 & 0.992 & 0.885 & 50 \\
$50 \Omega$ & $\mathrm{nH}$ & $\mathrm{pF}$ & $\mathrm{nH}$ & $\mathrm{pF}$ & $\mathrm{nH}$ & $\mathrm{pF}$ & $\mathrm{nH}$ & $\Omega$ \\
\hline
\end{tabular}


The ADS software enables us to represent the above transmission line parameters in circuit format as the values are applied for short circuit and open circuit sections of the transmission line. Below is the transmission line distributed circuit.

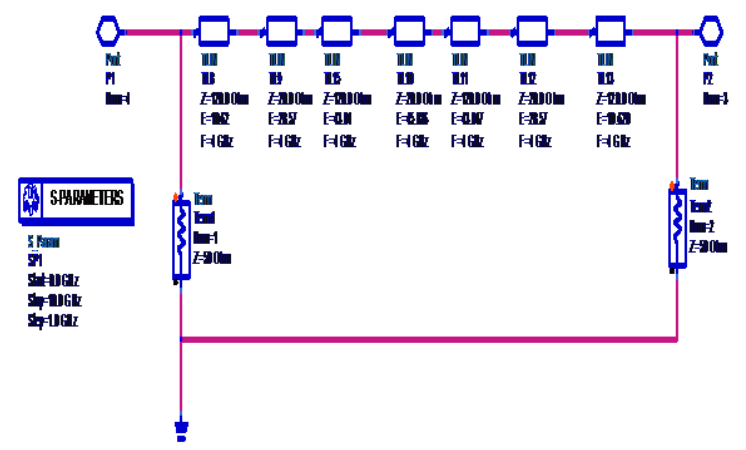

Figure 6. ADS representation of the distributed transmission line circuit

The characteristic of the distributed transmission line circuit was obtained by simulating the circuit using the ADS software and we were able to obtain similar frequency response as compared to the lumped maximally flat low-pass filter prototype. We obtained a cut-off of $4 \mathrm{GHz}$ for both $s_{11}$ and $s_{12}$ against frequency. It is of great importance to note that, $s_{12}$ and $s_{21}$ are symetrically equal. It was observed that when $s_{12}$ and $s_{21}$ was plotted on the same axis against frequency there was an interception at $4 \mathrm{GHz}$ which proves the fact that the design specification was achieved. The frequency responses of $s_{12}$ and $s_{21}$ are shown below.

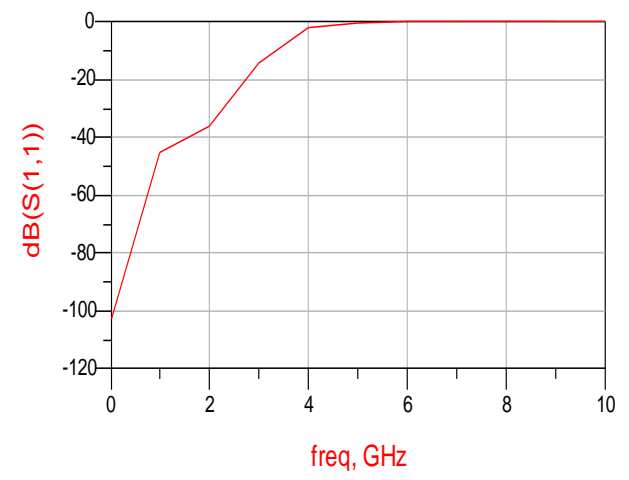

Figure 7. The characteristic of distributed transmission line showing variation of incident wave with frequency

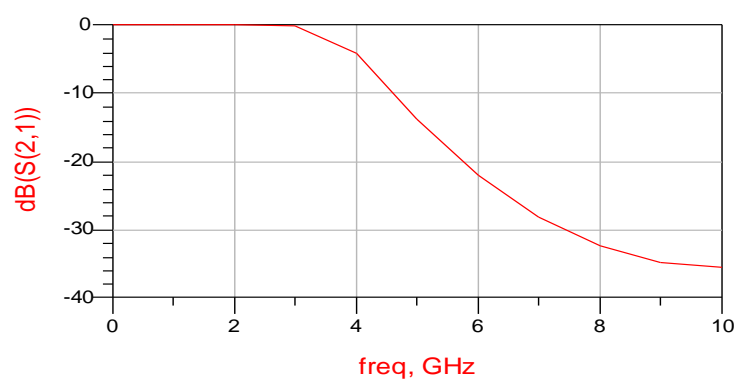

Figure 8. The characteristic of distributed transmission line showing variation of reversed gain with frequency

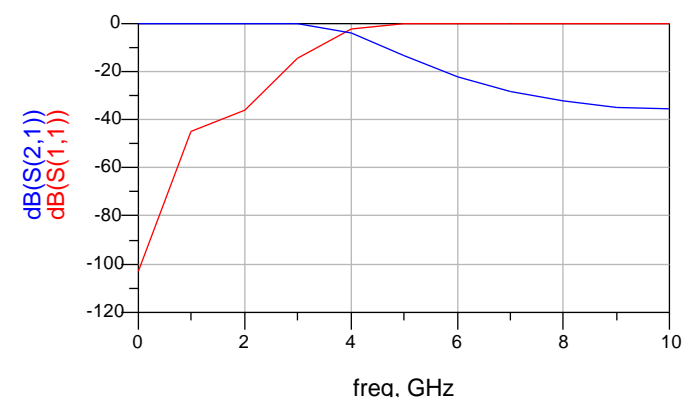

Figure 9. The characteristic of the distributed transmission line showing variation of both incident wave and the reversed gain with frequency

\section{RESULTS AND DISCUSIONS}

D. Layout of the Microstrip Structure for Maximally Flat (Butterworth) Filter

Based on the assumption that all transmission lines are realized in microstrip technology and the substrate has dielectric constant $\varepsilon_{r}=4.2$, rough $=0 \mathrm{~mm}$, mur $=1, \mathrm{H}=2.0 \mathrm{~mm}, \mathrm{Hu}=1.0$, cond $=1.0 \mathrm{e}+5, \quad \tan \delta=0.02, \mathrm{~T}=0.01 \mathrm{~mm}$ and using the above equations;

$L^{\prime}=R_{O} L, C^{\prime}=\frac{C}{R_{O}}, L=Z_{O L} \beta l, C=\frac{\beta l}{z_{o c}}$, where $R_{O}=50 \Omega$

\begin{tabular}{|c|c|c|}
\hline $\begin{array}{l}\text { Low pass } \\
\text { prototype }\end{array}$ & Impedance scale & $\begin{array}{l}\text { Electrical-length } \\
(\beta l) \text { in degrees }\end{array}$ \\
\hline$L_{1}=0.4450$ & 22.250 & 10.62 \\
\hline$C_{1}=1.2470$ & 0.0250 & 28.57 \\
\hline$L_{2}=1.8019$ & 90.095 & 43.02 \\
\hline$C_{2}=2.0$ & 0.040 & 45.84 \\
\hline$L_{3}=1.8019$ & 90.095 & 43.02 \\
\hline$C_{3}=1.2470$ & 0.0250 & 28.57 \\
\hline$L_{4}=0.4450$ & 22.250 & 10.62 \\
\hline
\end{tabular}


We were able to estimate the width and the length of the individual microstrip line.

\section{Table 4. Shows Distributed Parameters of Microstrip} Maximally Flat low-pass filter.

\begin{tabular}{|c|c|c|c|c|}
\hline $\begin{array}{l}\text { Distributed } \\
\text { component }\end{array}$ & $\begin{array}{l}\text { Impedance } \\
\text { scale }\end{array}$ & $\begin{array}{l}\text { Electrical- } \\
\text { length } \\
(\beta l) \text { in degrees }\end{array}$ & $\begin{array}{l}\text { Width } \\
(\mathrm{mm})\end{array}$ & $\begin{array}{l}\text { Length } \\
(\mathrm{mm})\end{array}$ \\
\hline$L_{1}$ & 22.250 & 10.62 & 0.549 & 1.309 \\
\hline$C_{1}$ & 0.0250 & 28.57 & 14.70 & 3.085 \\
\hline$L_{2}$ & 90.095 & 43.02 & 0.549 & 5.304 \\
\hline$C_{2}$ & 0.040 & 45.84 & 14.70 & 4.950 \\
\hline$L_{3}$ & 90.095 & 43.02 & 0.549 & 5.304 \\
\hline$C_{3}$ & 0.0250 & 28.57 & 14.70 & 3.085 \\
\hline$L_{4}$ & 22.250 & 10.62 & 0.549 & 1.309 \\
\hline
\end{tabular}

Below is an ADS representation of the microstrip filter structure.

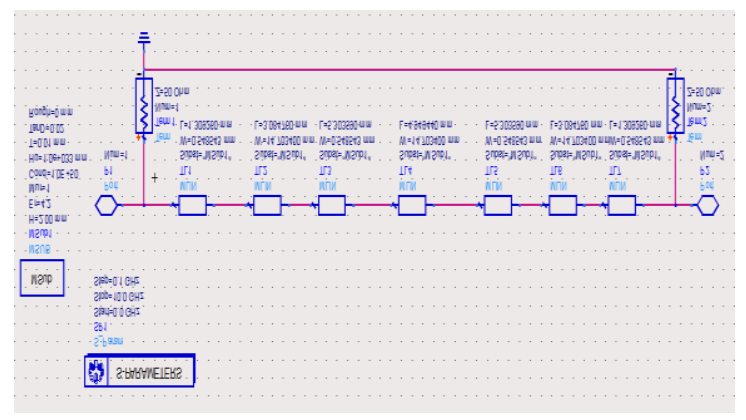

Figure 10. After simulating the ADS the following characteristics of the microstrip were obtained and the microstrip layout was obtained.

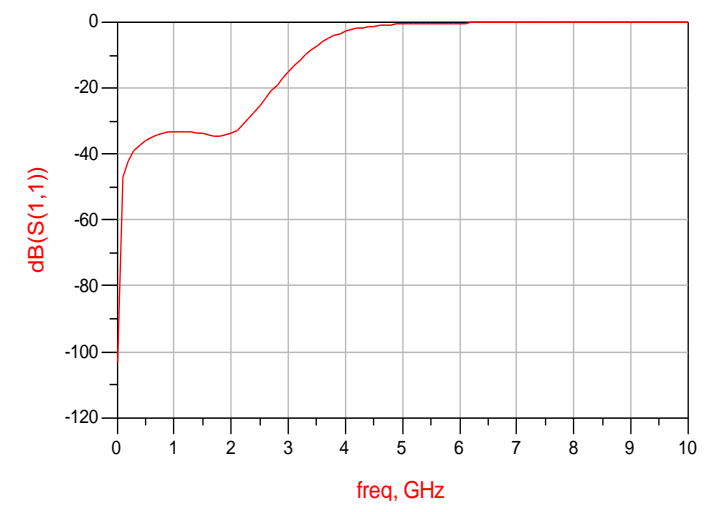

Figure 11. The characteristic of microstrip structure showing variation of incident wave with frequency

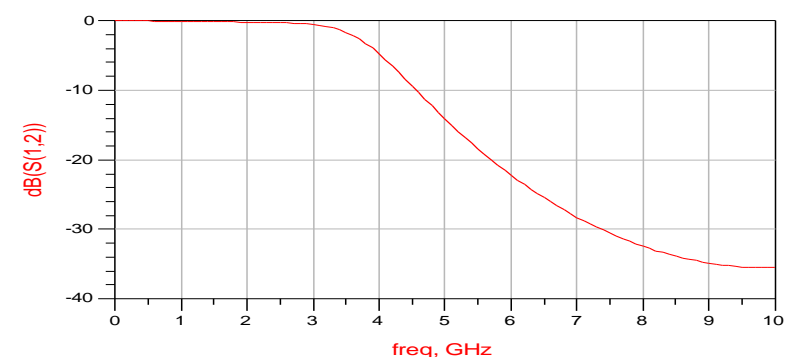

Figure 12. The characteristic of microstrip structure showing variation of reversed gain with frequency

The impulse response is not symmetric and as a result, the filter does not have a linear phase response. It can be seen that some of the widths are extremely thin and might be very hard to actually make in reality. This is one of the limitations of the stepped impedance filter design.

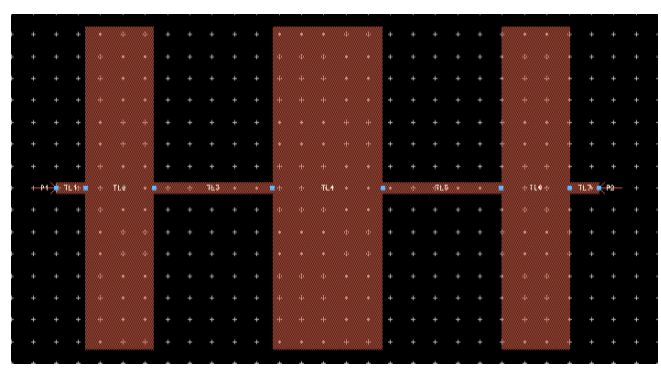

Figure 13. The microstrip filter structure for the maximally flat filter.

The frequency response of Figure 7 shows that the maximally flat filter has a wide roll-off and there was a distortion at the passband at $1.5 \mathrm{GHz}$ of $-40 \mathrm{~dB}$. The design specification was met as a cut-off frequency of $4 \mathrm{GHz}$ was achieved.

\section{CONCLUSION}

Stepped impedance microstrip low-pass filter for maximally flat filter with order $N=7$ was simulated using ADS 
software. The frequency response of the maximally flat filter shows that it has a wide roll-off and there was a distortion at the passband at $1.5 \mathrm{GHz}$ of $-40 \mathrm{~dB}$ but in the distributed circuit the distortion occurs at similar frequency at the $-20 \mathrm{~dB}$ point. The design specification was met as a cut-off frequency of $4 \mathrm{GHz}$ was achieved. attenuation at high frequency. In order to resolve this problem a higher order should be used at high frequency.

\section{ACKNOWLEDGMENT}

The authors also want to thank Dr. Nimibofa Ayawei for financial support to enable the publication of this article.

\section{REFERENCES}

[1] D. M. Pozar,"Microwave Engineering",Fourth Edition,Wiley and Sons, 2012.

[2] Rajasekaran, K., J. Jayalakshmi, and T. Jayasankar. "Design and analysis of stepped impedance microstrip low pass filter using ADS simulation tool for wireless applications." International Journal of Scientific and Research Publications 3, no. 8 (2013): 1-5.

[3] Bohra, Hussain, and Amrit Ghosh. "Design and Analysis of Microstrip Low Pass and Bandstop Filters." International Journal of Recent Technology and Engineering (IJRTE) 8, no. 3 (2019): 6944-6951.

[4] J. S. Hong, "Microstrip Filters for RF Microwave Applications" John Wiley and Sons, 2011.

[5] R. Ludwig, P. Bretchko, "RF Circuit Design: Theory and Applications", Publishing House of Electronics Industry, pp.147-153,169-173, 2004.

[6] S. N. Taib, M. A. Othman, W.N.A. Makhzan, T. S. M. Arshad, N. Y. M. Yasin, M. M. Ismail, M. H. Misran, “An Analysis of Low Pass Filter Using Bowtie Defected Ground Structure (DGS) at $10 \mathrm{GHz}$ for Radar Application”, 3rd International Conference on Instrumentation, Communications, Information Technology, and Biomedical Engineering (ICICI-BM E) Bandung, November 7-8, 2013.

[7] M. N. Mollah, Md. F. Hossain, J. S. Fu, D. H. Yang, "Novel Technique of Developing Microstrip Low Pass Filter (LPF)", ICICS 2007.

[8] A. Boutejdar, A. Omar, A. Batmanov, E. Burte, "New Low-Pass Filter Design Using Compensated Microstrip Capacitor and Coupled Meander Defected Ground Structure (DGS)", IEEE 2008.

[9] M. F. bin MdIdros, S. F. Abu Hassan, "A Design of Butterworth Low Pass Filter's Layout Based on the Effect of Filter's Order on the Ideal Filter Approximation", Symposium on Industrial Electronics and Applications (ISIEA 2009), October 4-6, 2009, Kuala Lumpur, Malaysia, IEEE 2009.

[10] K. Gholamreza, A. Lalbakhsh, K. Dehghani, and H. Siahkamari. "Analysis of novel approach to design of ultra-wide stopband microstrip low-pass filter using modified u-shaped resonator." ETRI Journal 37, no. 5 (2015): 945-950.

[11] Hayati, Mohsen, Farzin Shama, and Hamed Abbasi. "Compact microstrip lowpass filter with wide stopband and sharp roll-off using tapered resonator." International Journal of Electronics 100, no. 12 (2013): 1751-1759.
[12] M. Gholamhosein, M. Dousti, and A. Ebrahimi. "Design and fabrication of a compact microstrip low-pass filter with ultra-wide stopband and sharp rolloff-rate." Journal of Electromagnetic Waves and applications 32, no. 6 (2018): 713-725.

[13] S. Shreyasi, R. K. Manjunath, and P. Shanthi. "Design, simulation and fabrication of a microstrip bandpass filter." International Journal of Science and Engineering Applications 3, no. 5 (2014): 154-158.

[14] J. Akinwande, and Do S. Nyitamen. "2GHz microstrip low pass filter design with open-circuited stub." IOSR-Journal of Electronics and Communication Engineering 13, no. 2 (2018): 1-9.

[15] Salama, S., Y. Battah, and A. Abuelhaija. "Stepped Impedance 7th order Maximally Flat Low Pass Filter Using Microstrip Line for X-Band Applications." In Journal of Physics: Conference Series, vol. 1803, no. 1, p. 012005. IOP Publishing, 2021.

\section{AUTHORS}

First Author- Ayibapreye Kelvin Benjamin, Ph.D in Computing and Electronic Systems University of Essex, United Kingdom, M.Sc. in Electronic Communications and Computer Engineering, The University of Nottingham, United Kingdom, B.Eng. Electrical/Electronic Engineering, Niger Delta University, Nigeria, Niger Delta University, Wilberforce Island Bayelsa State, Nigeria. ayibapreyebenjamin@ndu.edu.ng

Second Author- Priye Kenneth Ainah, Ph.D in Renewable Energy Systems, Capetown, South Africa, M.Sc. in Renewable Energy Systems, The University of Nottingham, United Kingdom, B.Eng. Electrical/Electronic Engineering, Niger Delta University, Nigeria, Niger Delta University, Wilberforce Island Bayelsa State, Nigeria.priyeainah@yahoo.com

Third Author- Animiosevbuse Tosan Enoma, B.Eng. Mechanical Engineering, Ambrose Ali University Ekpoma, Edo State, Nigeria, Niger Delta University, Wilberforce Island Bayelsa State, Nigeria.enomakenzma@gmail.com

Correspondence Author- Ayibapreye Kelvin Benjamin, Ph.D in Computing and Electronic Systems University of Essex, United Kingdom, M.Sc. in Electronic Communications and Computer Engineering, The University of Nottingham, United Kingdom, B.Eng. Electrical/Electronic Engineering, Niger Delta University, Nigeria, Niger Delta University, Wilberforce Island Bayelsa State, Nigeria. ayibapreyebenjamin@ndu.edu.ng 